\title{
THERMAL AND STRUCTURAL ANALYSIS OF A BEAM STOP
}

\author{
Snezana Konecni, Ross E. Meyer*, and David Ireland* \\ SNS-3, ${ }^{*}$ ESA-DE, Los Alamos National Laboratory \\ Los Alamos, New Mexico 87545
}

\begin{abstract}
This paper addresses the evolution, design, analysis and development of a novel approach for stopping the proton beam at a $7.5 \mathrm{MeV}$ power level. During commissioning of the Spallation Neutron Source (SNS) injector, the first Drift Tube Linac (DTL) tank will be installed, and in the place of the second DTL tank a diagnostic plate assembly will be inserted and the beam thoroughly tested. The beam will be tested at full power $(36 \mathrm{~mA}, 1 \mathrm{~ms}, 60 \mathrm{~Hz})$, so a beam stop is being designed to handle the thermal and structural stresses and minimize neutron production. The beam stop is assumed to be a cone configuration with radius of $10 \mathrm{~cm}$ base and slope of $3.5 \mathrm{~cm} / \mathrm{cm}$. It will be made of Nickel 200, $2 \mathrm{~mm}$ thick.
\end{abstract}

\section{INTRODUCTION}

The Spallation Neutron Source (SNS) is an acceleratorbased facility that produces pulsed beams of neutrons by bombarding a mercury target with intense beams of 1$\mathrm{GeV}$ protons. Los Alamos National Laboratory is responsible for the design, fabrication, installation, and testing of the normal-conducting section of the Linear Accelerator (linac) for the SNS project. The normalconducting linac accepts a beam from the front end system and accelerates it from $2.5 \mathrm{MeV}$ to $187 \mathrm{MeV}$. The linac consists of a drift-tube linac (DTL) up to $87 \mathrm{MeV}$ and a coupled-cavity linac (CCL) up to $188 \mathrm{MeV}$. The DTL operates at an RF resonant frequency of $402.5 \mathrm{MHz}$, while the CCL operates at $805 \mathrm{MHz}$.

An ogive-shaped beam stop was successfully implemented in the first and second beam stop for the Low Energy Demonstration Accelerator (LEDA) of the Accelerated Production of Tritium (APT) project [1,2]. Nickel ogive-shaped beam stop was built for a lower level injector testing [1], and later carbon-carbon beam stop was built testing the RFQ to $6.7 \mathrm{MeV}$ and $100 \mathrm{~mA}$. The first beam stop was made out of nickel in order to minimize the neutrons per proton ratio while being structurally compatible with the vacuum and cooling water requirements. The second beam stop was made of carbon-carbon with $2 \mathrm{~mm}$ nickel electrodeposited to satisfy vacuum and water pressure loads.

\section{DESIGN CONSIDERATIONS}

Table 1 summarizes the beam stop design which is based on the conical shape. The conical beam stop will be integrated into an assembly that is placed on the same table with rest of beamline the equipment used for the diagnostic of the beam. Vacuum manifold of the Diagnostic Plate extends to the beam stop as well. Cooling water is supplied from the water cart of deionized water and its pressure increased by an high pressure additional pump placed close to the beam stop.

Table 1: Diagnostic Plate beam stop design

\begin{tabular}{|l|l|}
\hline Beam Characteristics & \\
Operation Pulse & $60 \mathrm{~Hz}$ \\
Duration & $7.5 \mathrm{MeV}$ at $36 \mathrm{~mA}$, Gaussian \\
\hline Physical Features & $1 \mathrm{~ms}$ \\
Dimensions & $30.5 \mathrm{~cm}$ ODx $44 \mathrm{~cm}$ Length \\
Beam Centerline length & $35 \mathrm{~cm}$ \\
Beam stop geometry & Axisymmetric cone \\
Beam stop Dimensions & $20 \mathrm{~cm}$ ID 35cm Length \\
Beam stop Material & Nickel 200 \\
Coolant & DI Water \\
Coolant flow direction & Rotational and counterflow \\
& to beam direction \\
\hline Thermal Management & \\
Total heat removed & $16 \mathrm{~kW}$ \\
Maximum Average Heat & $277 \mathrm{~W} / \mathrm{cm}^{2}$ (at the tip of the \\
Flux & cone) \\
Water flow rate & $0.00063 \mathrm{~m}^{3} / \mathrm{s}(10$ gpm) \\
Water pressure & $2.34 \mathrm{MPa}(340 \mathrm{psi})$ \\
Water velocity & $6.2 \mathrm{~m} / \mathrm{s}$ \\
Temperature rise & $6.5 \mathrm{C}$ \\
\hline Slope of the beam stop & $3.5 \mathrm{~cm} / \mathrm{cm}^{2}$ \\
& \\
\hline
\end{tabular}

\section{DESCRIPTION}

The elliptical spot shape of the SNS beam suggests a conical impact surface for the beam stop. The beam stop is assumed to be a hollow cone $2 \mathrm{~mm}$ thick with base radius of $10 \mathrm{~cm}$ base and slope of $3.5 \mathrm{~cm} / \mathrm{cm}$. The inside length of the cone is $35 \mathrm{~cm}$. The cone is cooled with water under pressure to prevent boiling.

Because of the beam shape, there is an azimuthal power distribution. The heat flux profile on the beam surface is dependent on the slope of the surface. Maximum heat flux is reached at the tip of the cone and it is $277 \mathrm{~W} / \mathrm{cm}^{2}$. The heat flux reduces along the surface of the cone so halfway, upstream, on the surface of the cone it is about $10 \mathrm{~W} / \mathrm{cm}^{2}$. The other half of the cone has almost no power applied onto it. The mentioned heat fluxes are the values 
along one of the axis of the beam. On the other axis they are slightly different. In order to simplify the analysis, it was assumed that the beam has circular shape and maximum values of the average heat flux were considered.

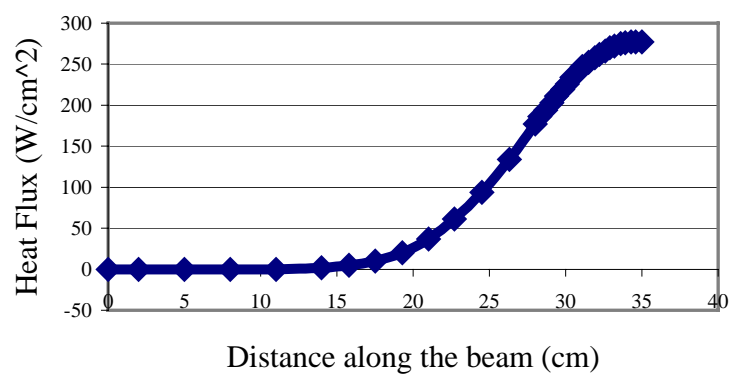

Figure 1: Maximum average heat flux along the beam axis

In order to effectively cool the beam stop water is circulated in a spiral channel. The channel is $2 \mathrm{~mm}$ high by $50 \mathrm{~mm}$ wide. These dimensions were chosen in order to keep high velocities of the water $(6 \mathrm{~m} / \mathrm{s})$ for a flow rate of $0.00063 \mathrm{~m}^{3} / \mathrm{s}(10 \mathrm{gpm})$ at $20 \mathrm{C}$. The inlet of the cooling channel is at the tip of the cone. Water is collected at the base of the cone and after the water pressure is reduced, returned to the water cart. Flow rate and pressure of the water are monitored at all times. A drop of pressure or insufficient flow rate will cause an emergency shutoff to prevent damage of the beam stop.

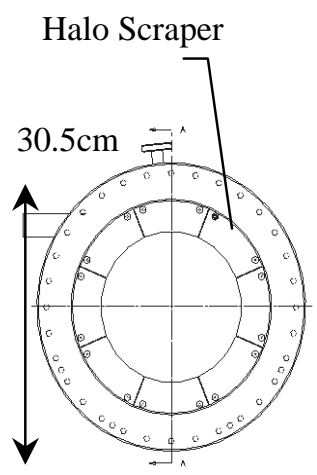

Vacuum Flange

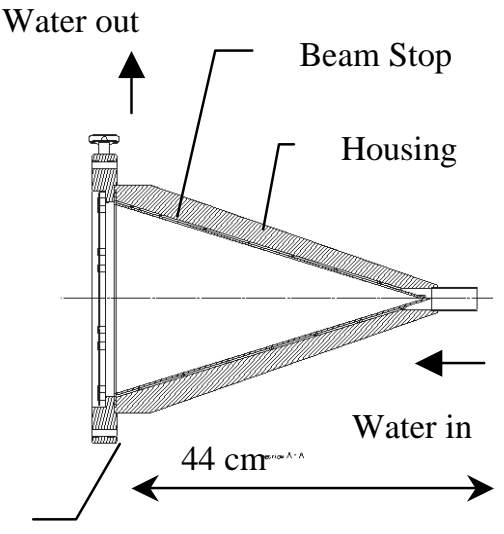

Figure 2: Conical beam stop welded assembly

\section{MATERIAL SELECTION}

Materials for the beam stop were selected based on thermal, mechanical and nuclear properties. Nickel 200 was chosen because of the good thermal and mechanical properties.

\section{ANALYSIS}

\subsection{Transient Analysis}

One-dimensional analysis was done to determine the effect of the pulsed beam on the diffusion within the Nickel plate. The Nickel plate is $3 \mathrm{~mm}$ thick for these calculations. Green's functions were used to solve the diffusion and it can be treated as an exact solution. Initially, it is assumed that the reference temperature is $20^{\circ} \mathrm{C}$. From this analysis it can be seen that if 4616 $\mathrm{W} / \mathrm{cm}^{2}$ is applied to the slab of thickness of $3 \mathrm{~mm}$, the surface temperature will reach $119^{\circ} \mathrm{C}$ in $1 \mathrm{~ms}$. After $1 \mathrm{~ms}$ the beam is off for $16 \mathrm{~ms}$ and during that time the temperature at the surface will drop to $32^{\circ} \mathrm{C}$, when the new beam pulse is applied, Figure 2 .

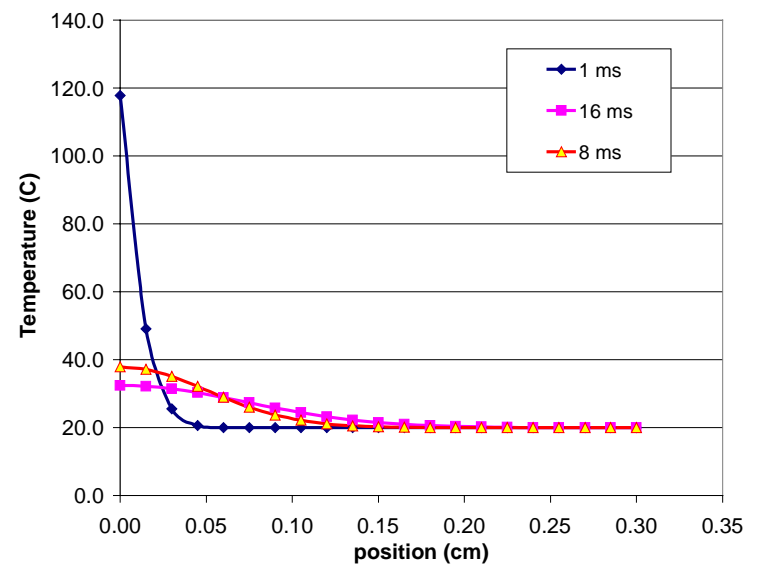

Figure 3. Transient calculations of the temperature in degrees $\mathrm{C}$ of a Nickel plate. The three lines are showing temperature with respect to the thickness at $1 \mathrm{~ms}, 8 \mathrm{~ms}$, and $16 \mathrm{~ms}$.

\subsection{Thermal and Structural Analysis results}

Two dimensional steady state analysis was performed with a finite elements code Ansys. Power distribution varies on the surface of the beam stop and the peak heat flux is $277 \mathrm{~W} / \mathrm{cm}^{2}$ at the tip of the cone. It is assumed that the flow is distributed into a spiral channel to maintain high water velocities. The direction of the water flow is opposite to the beam.

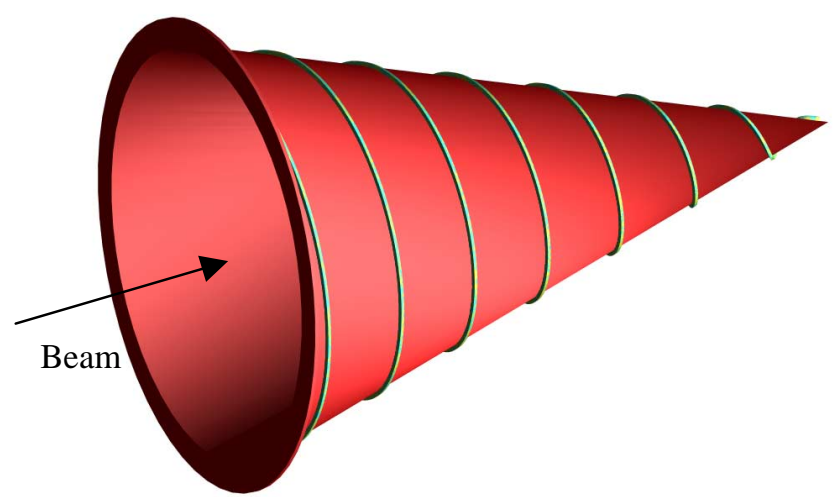

Figure 4. Beam stop with a spiral cooling channel.

Thermal and structural analysis was performed and the maximum temperature at the tip of the cone was calculated to be $185^{\circ} \mathrm{C}$. Figure 5 shows the temperature distribution in the beam stop assuming the maximum heat flux is at the tip of the cone 

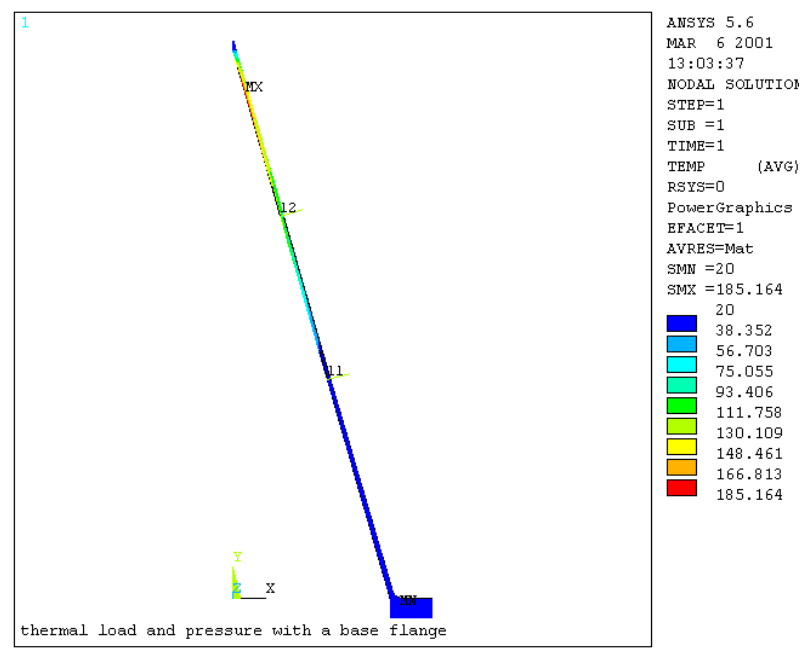

Figure 5. Temperature distribution in the nickel beam stop with a spiral cooling channel, degrees $\mathrm{C}$.

Figure 6 shows the stress contours in the beam stop assuming the maximum heat flux is at the tip of the cone and there is applied pressure from the cooling channel on the outside of the cone. Inside the cone is under vacuum. Maximum stresses are within the allowable yield strength for Nickel 200, which is $148 \mathrm{MPa}$.

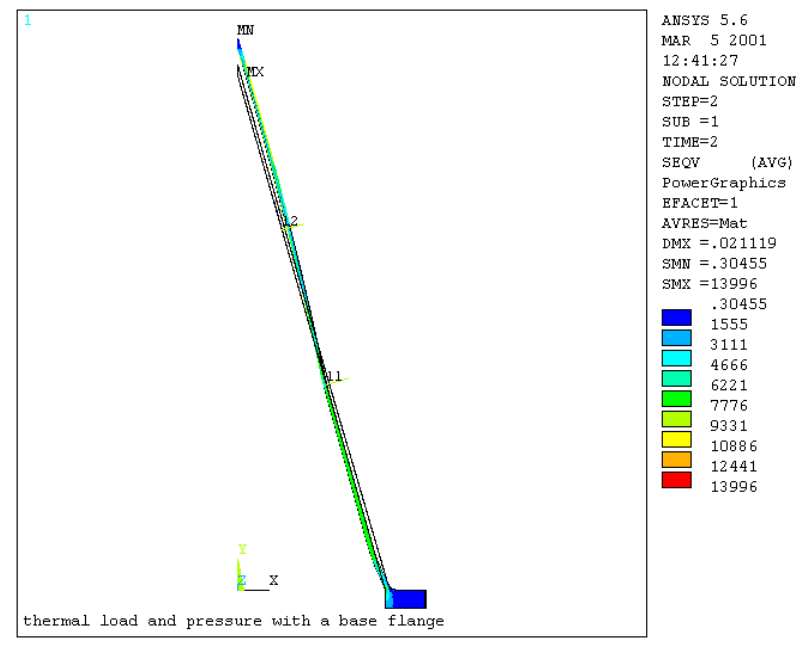

Figure 6. Von Mises stresses in the nickel beam stop with a spiral cooling channel, $\mathrm{N} / \mathrm{cm}^{2}$.

\section{DIAGNOSTIC PLATE ASSEMBLY}

Figure 7 shows the diagnostic plate assembly. The Beam Stop assembly is the conical item downstream end of the Diagnostic Plate. The assembly will be positioned after DTL tank 1 and used for diagnostic of the beam at full power.

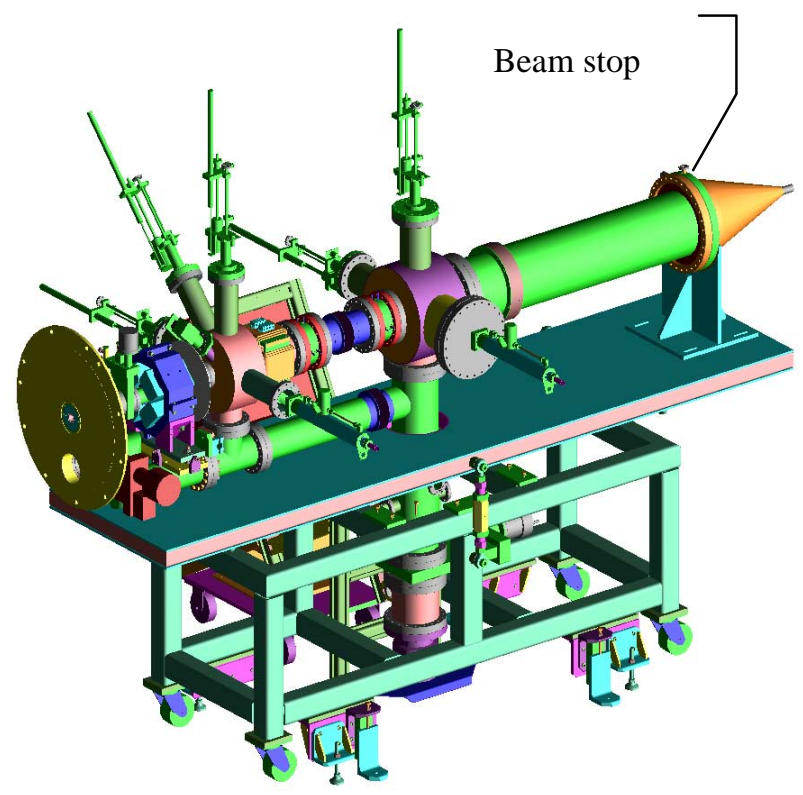

Figure 7. Diagnostic plate assembly

\section{CONCLUSION}

The Diagnostic plate beam stop has been designed and analyzed. The beam stop will stop a beam of protons at full power, $16 \mathrm{~kW}$. The beam stop is assumed to be a cone configuration with radius of $10 \mathrm{~cm}$ base and slope of 3.5 $\mathrm{cm} / \mathrm{cm}$. It will be made of Nickel 200, 2 mm thick.

\section{ACKNOWLEDGMENT}

Work supported by the Office of Basic Energy Science, Office of Science of the US Department of Energy, and by Oak Ridge National Laboratory.

\section{REFERENCES}

[1] T.H. Van Hagan, D.W. Doll, J.D. Schneider, F.R. Spinos," Design of an Ogive-Shaped Beamstop", Proceedings of the 1998 Particle Accelerator Conference, Chicago, June 1998

[2] R.T. Acharaya,, et al., " An Ogive Shaped CarbonCarbon composite Beam Stop", Proceedings of the 1999 Particle Accelerator Conference, New York, 1999. 